\title{
THE INFLUENCE OF TASK CONSTRAINTS ON ATTACKER TRAJECTORIES DURING 1V1 SUB-PHASES IN SOCCER PRACTICE
}

\author{
Filipe Clemente ${ }^{1}$, Micael Couceiro ${ }^{2}$, Fernando Martins ${ }^{3,4}$, Gonçalo Dias ${ }^{1}$, and Rui Mendes ${ }^{4,5}$ \\ ${ }^{1}$ RoboCorp, Faculty of Sport Sciences and Physical Education - University of Coimbra, \\ Portugal \\ ${ }^{2}$ RoboCorp, Engineering Institute of Coimbra - Polytechnic Institute of Coimbra, Portugal \\ ${ }^{3}$ Instituto de Telecomunicações, Covilhã, Portugal \\ ${ }^{4}$ RoboCorp, Coimbra College of Education - Polytechnic Institute of Coimbra, Portugal \\ ${ }^{5}$ Interdisciplinary Centre for the Study of Human Performance - Lisbon Technical \\ University, Portugal
}

\section{SUMMARY}

The task constraints are prevalent elements used by coaches to train their players in sports training (Araújo, 2006; Newel, 1986). The scope of this study focuses on the analysis of spatial occupation of the attacking player in the practice space, when subjected to certain instructional constraints, on $1 \mathrm{v} 1$ soccer sub-phase. This study analyzed 11 soccer players (17.91 \pm 1.04 years old) with $8.60 \pm 1.52$ years of practice. The heat maps presented differences on the occupied field surface in the various practice conditions. The analysis of variance of the duration of the offensive attempt also presented statistical differences within the various practice conditions $\left(F_{(2,327)}=30.776 ; p=.01\right)$. Results suggest that in risk situations the attacker tends to promote the space-time symmetry. On the other hand, when the instruction to keep the ball was given, unlike the risk constraint, there was a lateralization of the action, increasing the variability and dispersion of the attacker's trajectories. This study demonstrated the relevance of manipulating instructional constraints.

Key Words: Task Constraints, instruction, soccer, spatial occupation, heat maps.

\section{INTRODUCTION}

Task constraints may influence behaviour of athletes in different ways (Davids \& Araújo, 2005; Davids, Button, \& Bennett, 2008; Newell, 1986). The approach based on constraints (ABC approach) fits the acquisition of coordination patterns in sport (Araújo, Davids, Bennett, Button, \& Chapman, 2004; Davids et al., 2008), by contemplating the actions of the performer, the characteristics of the task and the environment (Araújo, 2006).

Constraints can restrict or enable multiple behaviors that the system can adopt (Davids et al., 2008). Specifically, task constraints can help the players to center their perception on specific information. Therefore, they include the rules that constrain spatial and temporal patterns of the movement dynamics during an activity that may be open to interpretation (Handford, Davids, Bennett, \& Button, 1997). It should be noted that individuals concerned with the acquisition of skill should consider the manipulation of significant constraints to achieve a desired response (Clemente \& Mendes, 2011a). For instance, a soccer coach may guide the search for a movement solution by imposing a rule constraint that only allows shots from outside the penalty area (Handford et al., 1997). Accordingly, the coach can use the constraints to improve the quality of the exercise, directing the players' perception to the information considered to be relevant (Clemente, Couceiro, Martins, \& Mendes, 2012a). The coach often uses the task constraints to implement the training content (Davids \& Araújo, 2005). In this sense, one of the main functions of the sports coach is to identify and manipulate the most important constraints that promote self-organization of the motor system behavior in a specific game (Vilar, Castelo, \& Araújo, 2010). In this viewpoint, the task constraints include the simplification of play 
rules, the number of players or the practice area (Figueira \& Greco, 2008), focusing on the performance of the practitioners and their specific goals (Clemente \& Mendes, 2011a; Clemente et al., 2012a).

In addition, the systematization of the game into subsystems, units or sub-phases allows the analysis of the game from the intra and inter-coupling between players (McGarry, Anderson, Wallace, Hughes, \& Franks, 2002). Thus, it is possible to define the relationship between players and teams on three levels: 1) inter-coordination, 2) intra and inter-coordination between players, and 3) intra and inter team coordination (Travassos, Araújo, Correia, \& Esteves, 2010).

Recent work on team sports studied the game sub-phases (1v1) (i.e., inter-coordination analysis), demonstrating the importance of manipulating task constraints (Araújo, 2006; Duarte et al., 2010b; Passos et al., 2008; Passos, Lopes \& Milho, 2008). Constraints such as field dimension, number of players or instructions provided by the coach can be useful in order to adjust the task to the players' specificity.

Therefore, the instruction provided by the coach is one of the task constraints that influence players' intention (Clemente \& Mendes, 2011b). Corroborating this, some recent studies (Araújo, 2006; Clemente \& Mendes, 2011b; Clemente, Mendes, \& Soler, 2011) demonstrate the pertinence of manipulating the instructions provided by the coach in order to improve the players' perception of the task, thus resulting in considerable changes in both process and product variables. In other words, within this context, the role of the feedback or the instruction may be considered as a way to amplify the environment information in order to guide the players toward finding ever improved solutions that satisfy the constraints imposed by the coach (Araújo, 2006; Davids \& Araújo, 2005).

In Araújo's (2006) study of basketball players in the 1v1 game sub-phase, it was shown that different instructions triggered different decisions from players. In fact, according to the author, the situations in which the instruction was to take risks, more time in a spatio-temporal symmetry was observed.

In Clemente and Mendes (2011b) and Clemente et al. (2011), the 1v1 sub-phase in youth soccer players showed that the attacker (i.e., the player with ball possession) performed the task under the influence of three types of instructional constraints (e.g., risk, neutral and conservative). It was highlighted that in the three instructional constraints, the main objective was to successfully complete the offensive attempt, i.e., scoring the goal.

Through the analysis of the product variable (i.e., notational analysis) under- 12 soccer players (Clemente $\&$ Mendes, 2011b), it was possible to verify statistically significant differences between the instructional constraints, regarding the time of the offensive attempt, bipedal recurrence, frequency to overtake the defender, the ball losses and the frequency of shots to the goal.

In summary, the reviewed studies about instructional constraints (e.g., take risks or keep the ball) suggest that it is possible to conclude that risk and conservative instructions present significant differences between them, concluding that the coach can guide the players' performance using instruction constraints, thus resulting in different actions (Araújo,

FIGURE 1

Illustrative image of a frame obtained in the course of a trial.

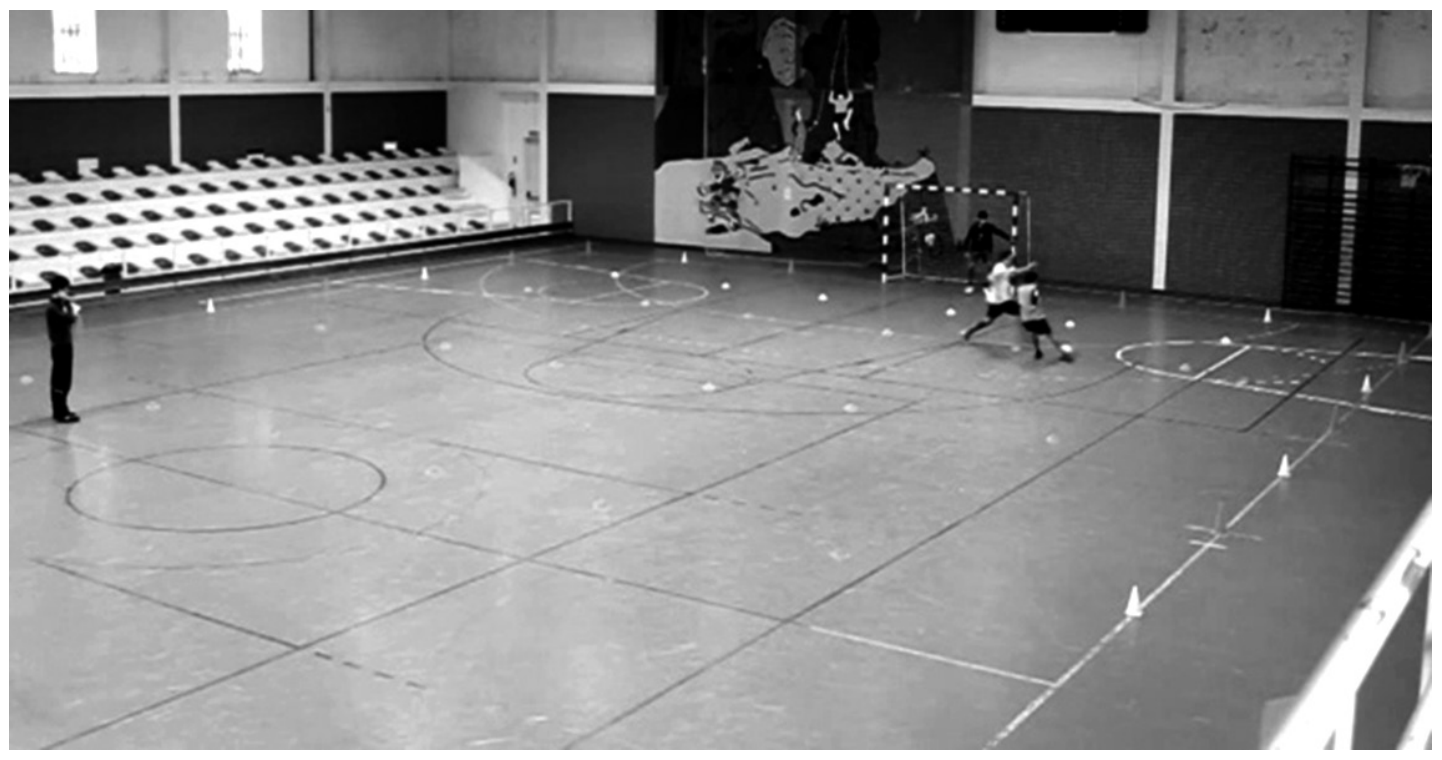


2006; Clemente \& Mendes, 2011b; Clemente et al., 2011).

However, the studies about the instructional constraints only consider the notational analysis disregarding the kinematical variables, as well as the trajectories made by players in the different task conditions. In fact, if the time in the conservative instruction increases, it is possible that players' would perform different trajectories in order to avoid the opponent and, at the same time, keep the ball to attack in the correct instant.

Therefore, the main objective of this study is to analyze the spatial trajectories of soccer players in 1v1 sub-phase with goalkeeper. Moreover, we intend to analyze the paths performed by players on the pitch when affected by the task constraints, thus mapping the spatial trajectories of athletes with heat maps.

\section{METHODS}

\section{Participants}

This study analyzed 11 male soccer players of federated teams from Coimbra district (Portugal), of $17.91 \pm 1.04$ years old, and with $8.60 \pm 1.52$ years of practice.

\section{Experimental Design}

A soccer game sub-phase (i.e., 1v1 with goalkeeper) was implemented in a scenario of 19.6 meters (m) wide by $18 \mathrm{~m}$ long, with markers at the edges of the field (Figure 1).

At the beginning of each trial, the defender was located $6 \mathrm{~m}$ away from the striker, positioned in the center of the field, a distance of $18 \mathrm{~m}$ from the goal. Moreover, the goalkeeper was restricted to his goal line.

The task consisted in the realization of a soccer offensive attempt (i.e., score a goal) by the attacker in a $1 \mathrm{v} 1$ situation with a goalkeeper.

\section{Task Conditions}

Participants interacted in 1v1 situations with goalkeepers. Each participant performed the task under the influence of three types of instructional constraints: 1) conservative, 2) risk, and 3) neutral. In the conservative instruction, the attacker was informed that his team was winning and thus attacked whenever he had the opportunity. In the risk instruction, the attacker was informed that the game would soon end and that his team was loosing thus resulting in a risky behavior. Finally, in the neutral instruction, it was reported that the attacker should try to score a goal. In all practice conditions the main goal of the task was to score a goal.
In each of the three practice conditions (i.e., conservative, risk and neutral) 10 trials were performed. Prior to the study, an offensive attempt was provided to each participant for them to understand the main objective of the task and in order to verify if the players understood all the procedures.

In each practice condition, the attacker was told to perform the test using offensive kicking (i.e., score a goal). On the other hand, it was reported to the defender that he should prevent the goal. Before the start of each trial, the instructional constraint was provided (i.e., conservative, risk or neutral), and the attacker began its offensive attempt. All trials followed the rules of organized soccer for this age group.

\section{Procedures}

The players' actions were captured using a digital SLR (Canon EOS 500D) with capacity to process images at $30 \mathrm{~Hz}$ (i.e., 30 frames per second). The camera was placed at $4.53 \mathrm{~m}$ above ground, in the sagittal plane, to capture the whole task (Figure 1). Official soccer balls were used for this specific age group of players. An orange vest and a yellow vest were used by the attacker and the defender, respectively. The players' trajectories were analyzed using MATLAB.

After capturing the soccer offensive attempts, the physical space was calibrated using direct linear transformation (DLT), which relates the object's position (e.g., players) in the metric space with the corresponding object in the image (Duarte et al., 2010a).

The mapping allowed the construction of frequency histograms based on the spatial distribution of the attacker, thus resulting in the graphical representation of heat maps.

For this purpose, the whole scene was split in a $20 \times 20$ matrix resulting in a resolution lower than 1 $\mathrm{m}^{2}$, thus obtaining a histogram representative of the more occupied zones of the field by a given player in a given practice condition. Figure 2 illustrates an example of a histogram.

To support the analysis of the occupied zones we proceeded to the design of heat maps. These heat maps consist of a graphical representation of the data in which the frequency values obtained by the spatial distribution histograms are represented in a two-dimensional table with different colors. The darker colors represent a higher occupation frequency in a certain area of the field.

In addition, to analyze the traveled distance, we also proceeded to the statistical analysis of required time the attackers needs to complete the offensive attempt in each practice condition. Therefore, we 
used the one-way ANOVA to establish the statistically significant differences between soccer players, in each practice condition. The assumption of normality distribution of one-way ANOVA in the three practice conditions (i.e., conservative, neutral and risk) was investigated using the Kolmogorov-Smirnov test with correction Lillefors. It was found that the distributions are not normal in the dependent variable. Although it was not normal, since $n=30$, using the Central Limit Theorem (Maroco \& Bispo, 2003; Pedrosa \& Gama, 2004) we assumed the assumption of normality (Akritas \& Papadatos, 2004). The analysis of homogeneity was carried out using the Levene test. It was found that there is no uniformity of practice under the previously mentioned conditions. However, despite the lack of homogeneity, the F test (ANOVA) is robust to homogeneity violations when the number of observations in each group is equal or approximately equal (Pestana \& Gageiro, 2008; Maroco, 2010; Vicent, 1999), which is the case here. As with the assumption of normality, violation of this assumption does not radically change the $F$ value (Vicent, 1999). Additionally, we used the Games-Howell post hoc test (Laureano, 2011). This analysis was performed using the IBM SPSS program (version 19) for a significance level of $5 \%$.

\section{RESULTS}

Histograms were used to quantify players' trajectories in the physical space, hence individual heat maps (Figure 3), allowing changes to be observed in the trajectories of the attacking players, subject to differentiated instructional constraints (i.e., conservative, risk and neutral).

\section{FIGURE 2}

\section{Illustrative image of a bistogram representative of the busiest areas of the field by a player in a given condition of practice.}

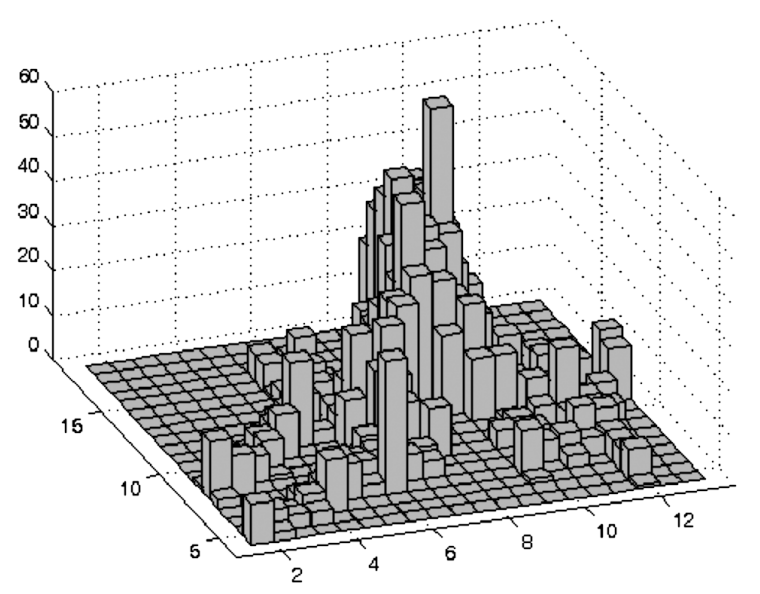

We verified a decrease in dispersal areas covered by the attacker, under neutral and risk instructional constraints, the occurrence of vertical ball driving zones being evident, i.e., the attacker centralizes its action and trajectory toward the goal. On the other hand, due to the conservative instructional constraint, there is a trajectory of lateralization (i.e., higher occupation of the side zone), thus presenting a greater space dispersion.

Figure 4 illustrates a player's tendency to go left of the practice area. However, despite this trend, there is a gradual vertical direction of the player toward the neutral and risk instructional constraints. We highlight the existence of trajectories in a close relation to the player's objective, when influenced by neutral and risk instructional constraints.

The one-way ANOVA made for the time of offensive attempt showed statistical differences between practice conditions $\left(F_{(2,327)}=30.776 ; p=.01\right)$.
Specifically, the post hoc test, showed differences between risk constraints and conservative constraints $(p=.01)$ and neutral constraints $(p=.01)$. Under the influence of risk constraints, players took less time to complete the offensive attempt when compared to the remaining constraints. Likewise, conservative constraints presented statistically significant differences for the neutral constraints $(\phi=.035)$, taking longer to complete the offensive attempt.

\section{DISCUSSION}

The aim of this study was to analyze the influence of instructional constraints on trajectories of the attacker. Additionally, a statistical analysis was performed in order to differentiate the time spent by the players to complete each offensive attempt in different instructional constraints. 
FIGURE 3

Representative heat maps of frequency of trajectories in space.

Conservative
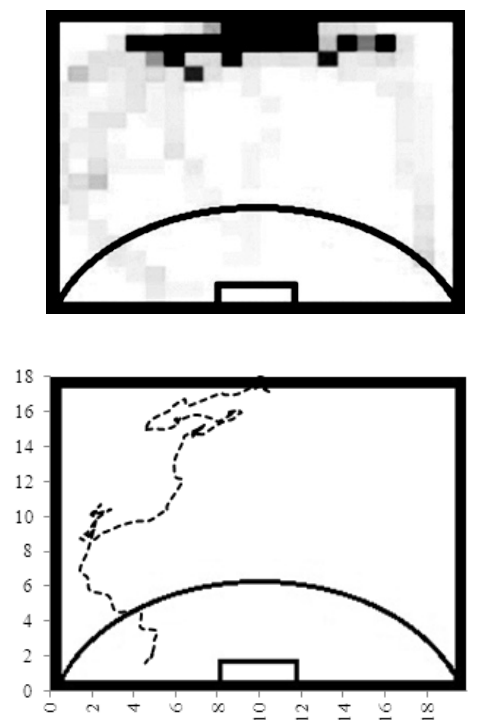

Neutral
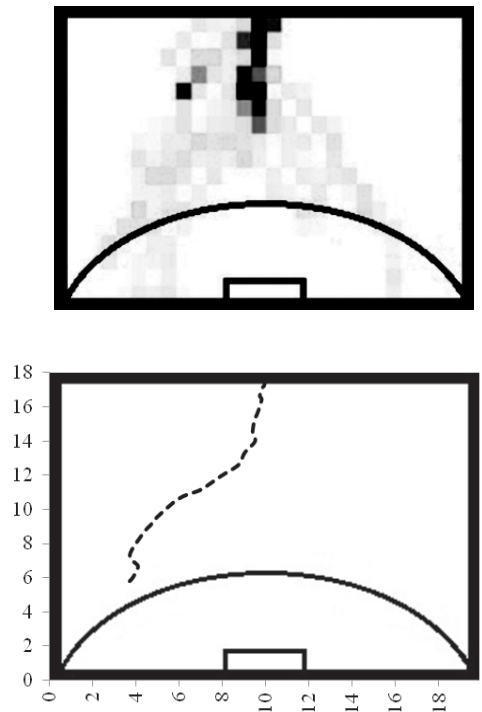

Risk
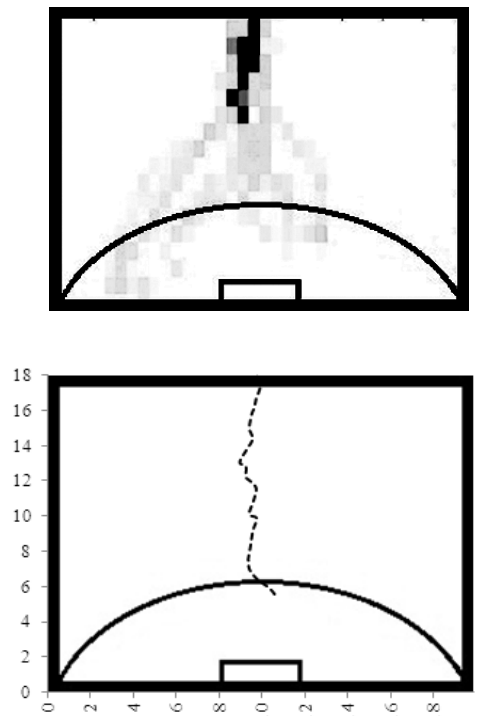

FIGURE 4

Representative heat maps of frequency of trajectories in space.

Conservative
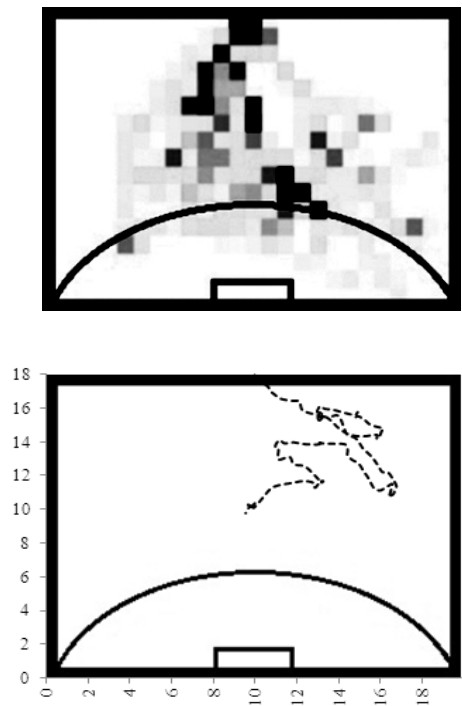

Neutral
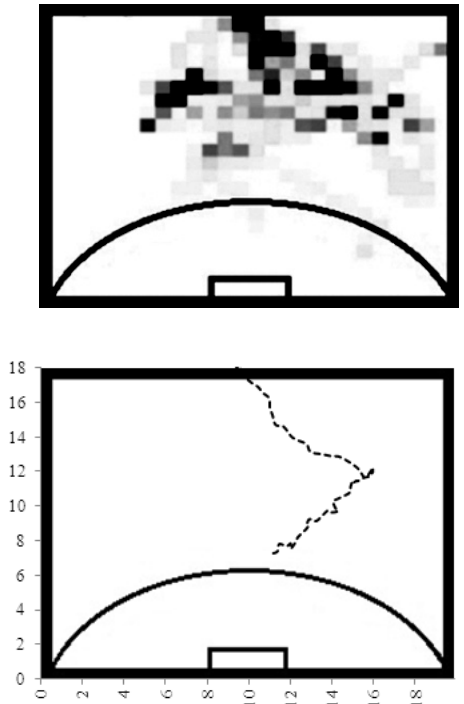

Risk
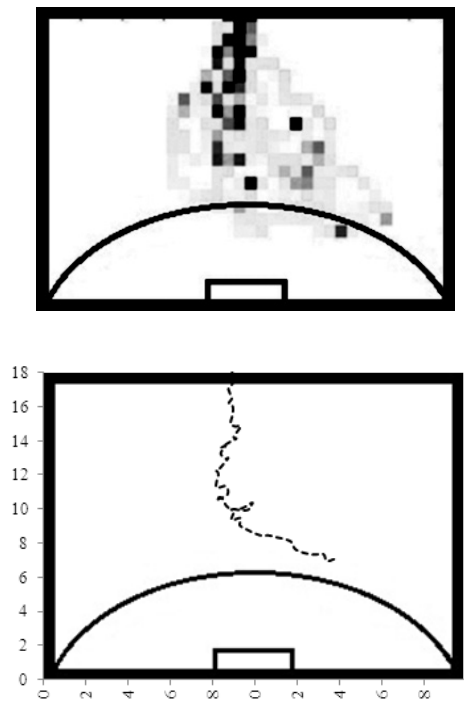

TABLE 1

Variance analysis between the 3 instructional constraints about time of offensive attempt.

\begin{tabular}{lccc}
\hline Instructional Constraints & Risk & Conservative & Neutral \\
\hline Risk & - & $.01^{* *}$ & $.01^{* *}$ \\
\hline Conservative & $.01^{* *}$ & - & $.03^{*}$ \\
\hline Neutral & $.01^{* *}$ & $.03^{*}$ & - \\
\hline$* p \leq .05$ & & & \\
$* * p \leq .01$ & & &
\end{tabular}


The data shows that when players were subjected to risk instructional constraint they presented a vertical action (i.e., driving the ball toward the goal) and reduced the variability of the trajectories, thus avoiding the sidelines of the field. Similar results may be observed in Araújo (2006), where basketball players with ball possession traveled with less variability over the field in order to complete the offensive attempt in the less possible time. In risk constraints, the player's behavior is distinguished showing space-time symmetry toward the goal, thus reducing the variability of the system. Under risk constraints, the completion time is smaller and statistically significant when compared to other constraints. These results are in line with Araújo (2006), Clemente and Mendes (2011b) and Clemente et al. (2011) where players who received instructions to take risk in offensive attempt reduced the action variability in order to directly attack the goal. For instance, in Clemente and Mendes (2011b) study, it was possible to verify that in risk conditions, the attacker quickly overtakes the opponent and does not lose possession of the ball as usual. These results show that, in risk instructional constraints, players try to improve the opportunities to score by reducing the time in front of their opponent and trying to avoid him in order to follow directly to the shot, thus increasing the opportunities to score. The study by Clemente and Mendes (2011b) shows that in risk conditions the number of shots is significantly higher than in the other practice conditions (e.g., conservative and neutral). Similar results are found in the study by Clemente et al. (2011).

When the instruction to keep the ball was given, unlike the risk constraint, there was a lateralization of the action, thus increasing the variability and dispersion of the attacker's trajectories. Confirming the results of Araújo (2006), Clemente and Mendes (2011b) and Clemente et al. (2011), it was also found that there was a statistically significant increase in the time needed to complete the offensive attempt. It may be observed that the attacker exploits all the available space to maximize the possession time. However, the attempt to keep the ball may reduce the potentiality of the attacker action since he exposes more time in front of the opponent. Additionally, the results of Clemente and Mendes (2011b) show that in the conservative condition, players overtake the opponent more frequently than in risk conditions and also lose the ball in more occasions. These results are in line with the study by Clemente et al. (2011), which may indicate that the attacker needs to keep the ball before the shot being exposed to the opponent action, thus losing the ball in more occasions. Furthermore, it is possible to analyze in Clemente and Mendes (2011b) and Clemente et al. (2011) studies that in the conservative condition the number of shots are fewer than in risk condition.

In summary, the task constraints proved to be essential for the spatial distribution of players and the time needed for offensive attempt achievement. It was found that the spatial distribution of the attacking player varies depending on the type of instruction given. Based on the data obtained, the heat maps are particularly useful to analyze the trends of athletes' trajectories in the game field, thus learning the actions that may contribute to the notational analysis. In other words, without the use of heat maps, it would not be possible to detect the type of action that led to the decreased or increased time in the offensive attempt, in the different practice conditions. In fact, traditional quantitative analysis (i.e., notational analysis) may not be suitable to establish the whole characteristics of a specific skill or tactical behaviour. Nevertheless, the use of new methods, such as tactical metrics, may enable the overcoming of the limitation inherent to the notational analysis. Therefore, the notational or kinematical analyses need to be complemented with new methods in order for the team's tactical dynamics to be understood (Clemente, Couceiro, Martins, \& Mendes, 2012b). This kind of information is vital to improve the knowledge of the game, quality of training and intervention of the coach, thus improving the collective performance of teams or players.

\section{CONCLUSION}

The instructional constraints imposed on the task proved to be important to influence the players' actions in the $1 \mathrm{v} 1$ game sub-phase. Within this context and given the analysis carried out above, it is clear that the instructions provided by the coach are a constraint that influences the players' performance, thus proving their potentiality to improve the quality of teaching and training exercises (Clemente \& Mendes, 2011b; Clemente et al., 2011).

Moreover, the obtained data shows that it is possible to prove the importance of using new methods of kinematic analysis, such as heat maps, in order to analyze the behavioral trends and patterns of players in field.

\section{REFERENCES}

Akritas, M. G., \& Papadatos, N. (2004). Heteroscedastioc One-Way ANOVA and Lack-of-Fit Tests. Journal of the American Statistical Association, 
99(466), 368-390. doi: 10.1198/01621450 4000000412

Araújo, D. (2006). Tomada de Decisão no Desporto [Decision-making in Sport]. Cruz Quebrada, POR FMH Edições.

Araújo, D., Davids, K., Bennett, S.J., Button, C., \& Chapman, G. (2004). Emergence of sport skills under constraint. In A. M. Williams and N. J. Hodges (Eds.), Skill Acquisition in Sport: Research, Theory and Practice (pp. 409-433). London, GBR: Routledge, Taylor \& Francis.

Clemente, F., Couceiro, M., Martins, F. M. L., \& Mendes, R. (2012a). The usefulness of smallsided games on soccer training. Journal of Physical Education and Sport, 12(1), 93-102.

Clemente, F., Couceiro, M., Martins, F. M. L., \& Mendes, R. (2012b). Team's Performance on FIFA World Cup 2011: Study based on Notational Analysis. Journal of Physical Education and Sport, 12(1), 13-17.

Clemente, F., \& Mendes, R. (2011a). Aprender o jogo jogando: uma abordagem transdisciplinar [Learning the game through the playing: A multidisciplinary approach]. Revista Cientifica Exedra, 5(1), 27-36.

Clemente, F., \& Mendes, R. (2011b). Constrangimentos instrucionais em futebolistas sub-12 na sub-fase de jogo 1 x 1 com guarda-redes [Instructional Constraints in U-12 soccer players at the $1 \mathrm{v} 1$ sub-phase with goalkeeper]. In P. Mouroço, O. Vasconcelos, J. Barreiros, and R. Matos (Eds.), Estudos em Desenvolvimento Motor da Criança IV (pp. 146-152). Leiria, POR: ESECS/IPL.

Clemente F, Mendes, R., \& Soler, F. C. (2011). Constrangimentos instrucionais em futebolistas sub18 na sub-fase de jogo 1x1 com guarda-redes Instructional Constraints in U-18 soccer players at the $1 \mathrm{v} 1$ sub-phase with goalkeeper]. Revista Portuguesa de Ciências do Desporto, 11, supl. 4, 45.

Davids, K., \& Araújo, D. (2005). A abordagem baseada nos constrangimentos para o treino desportivo [The Constraints-led Approach in Sport Training]. In D. Araújo (Ed.), O Contexto da Decisão - A acção táctica no desporto (pp. 35-60). Lisboa, POR: Visão e Contextos, Lda.

Davids, K., Button, C., \& Bennett, S. (2008). Dynamics of Skill Acquisition: A Constraints-Led Approach. Champaign, IL: Human Kinetics.

Duarte, R., Araújo, D., Fernandes, O., Fonseca, C., Correia, V., Gazimba, ... Lopes, J. (2010a). Capturing complex human behaviors in representative sports contexts with a single camera.

Medicina (Kaunas), 46(6), 408-414. doi: 10.2174/ 1875399X01003010016
Duarte, R., Araújo, D., Gazimba, V., Fernandes, O., Folgado, H., Marmeleira, J., \& Davids, K.

(2010b). The Ecological Dynamics of 1v1 SubPhases in Association Soccer. The Open Sports Sciences Journal, 3, 16-18.

Figueira, F. M., \& Greco, P. J. (2008). Futebol: um estudo sobre a capacidade táctica no processo de ensino-aprendizagem-treinamento [Soccer: Study about the tactical knowledge in the teaching-learning-training process]. Revista Brasileira de Futebol, 1(2), 53-65.

Handford, C., Davids, K., Bennett, S, \& Button, C. (1997). Skill acquisition in sport: Some applications of an evolving practice ecology. Journal of Sport Sciences, 15(6), 621-640. doi: 10.1080/ 026404197367056; PMid: 9486439

Laureano, R. M. (2011). Teste de Hipóteses com o SPSS. O meu manual de consulta rápida [Hypothesis' tests in SPSS. My manual for quick consultation]. Lisboa, POR: Edições Sílabo.

Maroco, J., \& Bispo, R. (2003). Estatística Aplicada às Ciências Sociais e Humanas [Applied Statistics at the Social and Human Sciences]. Lisboa, POR: Climepsi Editores.

Maroco, J. (2010). Análise Estatística com o PASW Statistics [Statistical Analysis with PASW Statistics]. Lisboa, POR: Edições Sílabo.

McGarry, T., Anderson, D., Wallace, S., Hughes, M., \& Franks, I. (2002). Sport competition as a dynamical self-organizing system. Journal of Sports Sciences, 20, 771-781. doi: 10.1080/026404102 320675620; PMid: 12363294

Newell, K. M. (1986). Constraints on the development of coordination. In M. G. Wade \& H. T.

A. Whiting (Eds.), Motor Development in Children: Aspects of Coordination and Control (pp. 341-360). Dordrecht, NED: Martinus Nijhoff.

Passos P., Araújo, D., Davids, K., Gouveia, L., Milho, J., \& Serpa, S. (2008). Information-governing dynamics of attacker-defender interactions in youth rugby union. Journal of Sports Sciences, 16(13), 1421-1429.

Passos, P, Lopes, R., \& Milho, J. (2008). Análise de padrões de coordenação interpessoal no umcontra-um no Futebol [Pattern Analysis of the Interpersonal Coordination in Soccer 1-a-side]. Revista Portuguesa de Ciência do Desporto, 8(3), 365-376. doi: 10.1080/02640410802208986; PMid: 18923958

Pedrosa, A. C., \& Gama, S. M. A. (2004). Introdução computacional à probabilidade e estatística [Introduction Computational Probability and Statistics]. Porto, POR: Porto Editora. 
Pestana, M. H., \& Gageiro, J. N. (2008). Análise de dados para as ciências sociais: A complementaridade do SPSS [Data Analysis for the Social Sciences: The complamentarity of the SPSS] (5th edition). Lisboa, POR: Edições Sílabo.

Travassos, B., Araújo, D, Correia, V., \& Esteves, P. (2010). Eco-Dynamics Approach to the study of Team Sports Performance. The Open Sports Sciences Journal, 3, 56-57. doi: 10.2174/1875399 X01003010056
Vincent, W. J. (1999). Statistics in Kinesiology (2nd Edition). Champaign, IL: Human Kinetics.

Vilar, L., Castelo, J., \& Araújo, D. (2010). Pressupostos para a conceptualização do exercício de treino de futebol. Um estudo realizado com treinadores com certificado de nível IV [Assumptions for the conceptualization of soccer training exercise. study of coaches with level IV certified]. Revista Gymnasium, 1(3), 121-142.

Received: July 7, 2011

Revision received: March 15, 2012

Accepted: April 2, 2012

Correspodence to:

Filipe Clemente, $\mathrm{PhD}$

Faculdade de Ciências do Desporto e Educação Física Estádio Universitário de Coimbra, Pavilhão 3

3040-156 Coimbra Portugal

E-mail: filipe.clemente5@gmail.com

Phone: 00351239802779

Fax: 00351239802779 